\title{
Using MODIS EVI to detect vegetation damage caused by the 2008 ice and snow storms in south China
}

\author{
Ji Chen ${ }^{1}$ and Liqun Sun $^{1}$ \\ Received 30 November 2009; revised 4 July 2010; accepted 7 July 2010; published 29 October 2010.
}

[1] This study develops a new method for detecting areas with severe vegetation damage caused by a serious ice and snow storm event that occurred in southern China over the period of 10 January to 2 February 2008. The new method adopts one of the Moderate Resolution Imaging Spectroradiometer (MODIS) MOD13A1 products, the enhanced vegetation index (EVI). Using a series of 16 day EVI maps at the $500 \mathrm{~m}$ spatial resolution in the 2008 growing season, the vegetation damage due to the event could be observed at a great number of patches, most of which are located outside of the regions with a flat topography. From a comparison of the MODIS Leaf Area Index (LAI), the Land Surface Temperature (LST) products, and the Landsat images obtained before and after the event, the severe vegetation damage is substantiated by a decreasing LAI, an increasing LST, and the "browning" of green vegetation in these patches. The analysis of topographic features discloses that the locations with the severe vegetation damage are mainly on slopes with easterly, southerly, and southeasterly aspects and in the moderate elevation region of between 500 and $700 \mathrm{~m}$. During the event period, most of the patches that exhibited vegetation damage had a minimum temperature slightly above $0^{\circ} \mathrm{C}$, experienced a minimum relative humidity of more than $75 \%$, and accumulated a precipitation depth of more than $130 \mathrm{~mm}$.

Citation: Chen, J., and L. Sun (2010), Using MODIS EVI to detect vegetation damage caused by the 2008 ice and snow storms in south China, J. Geophys. Res., 115, G00H04, doi:10.1029/2009JG001246.

\section{Introduction}

[2] Forest disturbance and recovery play a crucial role in the maintenance of the land surface biomass for local and global ecosystem services [Ozanne et al., 2003; Frolking et al., 2009]. Spaceborne remote sensing technology has been widely used to monitor land surface biomass [Frolking et al., 2009]. Numerous efforts using remote sensing products [e.g., Huete et al., 2002; White et al., 2005; Sims et al., 2006] have been made to understand vegetation variation.

[3] Ice storms can cause the decline of local land surface biomass. Generally, ice storms can occur due to a moist warm air mass overriding a colder air mass that is situated over a frozen ground surface [King et al., 2005; Ding et al., 2008]. When a raindrop falls from the warm air mass through the cooler air mass, it becomes supercooled and freezes upon impact with cold surfaces. Ice storms vary considerably in their severity and frequency and are one of the most devastating winter weather events [Hauer et al., 2006]. For example, an extreme ice storm occurred in January 1998 that resulted in significant forest damage across eastern North America [King et al., 2005].

\footnotetext{
${ }^{1}$ Department of Civil Engineering, University of Hong Kong, Hong Kong, China.

Copyright 2010 by the American Geophysical Union. 0148-0227/10/2009JG001246
}

[4] To analyze the severity of ice storm damage to vegetation, field surveys can provide first hand estimations of land cover losses [Tan et al., 2008]. However, field surveys can normally be conducted over a few patches, and they cannot give an overall picture in the evaluation of ice storm damage to vegetation for large areas. Therefore, remote sensing data have been used to map ice storm impacts at large spatial scales [e.g., King et al., 2005; Stueve et al., 2007]. King et al. [2005] used Landsat remote sensing and environmental data to locate the January 1998 ice storm damage to forests over eastern Ontario and southern Quebec in Canada. Stueve et al. [2007] used the Normalized Difference Vegetation Index (NDVI) remote sensing data, along with other field and satellite data, to investigate the spatial heterogeneity of forest damage caused by ice storms that affected the Appalachian Mountains in Virginia, USA, in 1994. The studies of King et al. [2005] and Stueve et al. [2007] had to rely on field data to identify the results obtained by using the remote sensing data. Furthermore, because the NDVI data may not be able to effectively depict the vegetation variation over well vegetated lands [Huete et al., 2002], the practicality of the NDVI to map damage to densely vegetated areas is still questionable.

[5] Fortunately, since 2000, the Moderate Resolution Imaging Spectroradiometer (MODIS) instrument has provided comprehensive land data products of new spectral bands at $500 \mathrm{~m}$ spatial and 16 day temporal resolutions [Justice et al., 1998]. The Enhanced Vegetation Index 


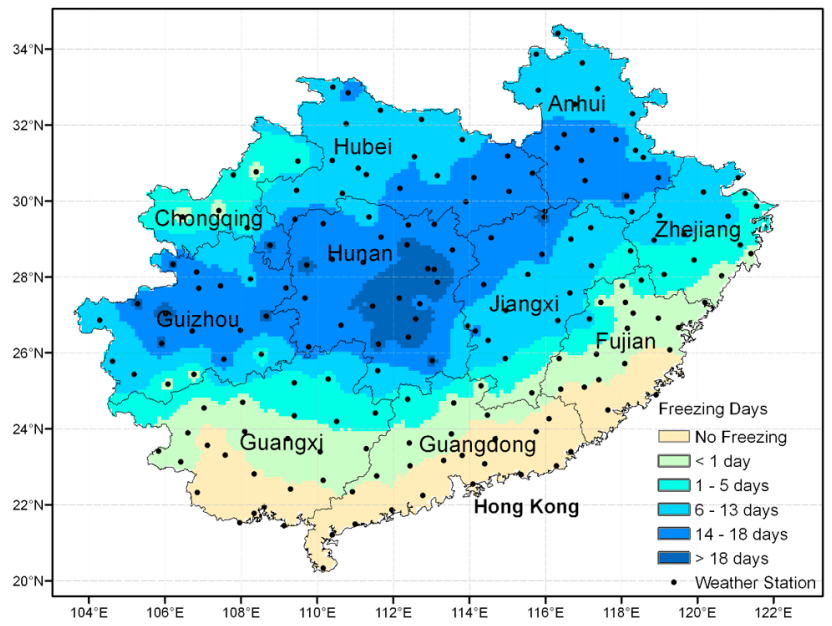

Figure 1. The locations of 186 weather stations. For each station, the number of freezing day is calculated by a standard (a day with precipitation depth more than $0 \mathrm{~mm}$ and average temperature below $1^{\circ} \mathrm{C}$ ) given by National Climate Center [2008]. The shaded areas present the different numbers of freezing days during the 2008 ice and snow storm event in south China.

(EVI), one of the MODIS products, is sensitive to the vegetation variation over densely vegetated regions [Huete et al., 2002]. Therefore, it is expected that the MODIS EVI data can be useful to map ice storm damage to vegetation. After the MODIS EVI product became available in 2000 , there was a severe ice and snow storm event that occurred from 10 January to 2 February 2008, in south China, which resulted in huge property losses and various natural biome disturbances [National Climate Center, 2008].

[6] The 2008 ice and snow storm event in southern China is an unprecedented disaster, both for its temporal persistence and spatial extent [Ding et al., 2008; National Climate Center, 2008]. After the event, a number of field surveys have been undertaken to investigate the damage to the vegetative land cover [e.g., Tan et al., 2008; Luo et al., 2008]. However, a systematic investigation of the ice and snow storm damage to vegetation at a regional scale is still missing. Such an investigation is valuable, not only to provide a complete picture of the vegetation damage, but also to evaluate the local biomass disturbance. Conse- quently, one of the objectives of this study is to use the MODIS EVI to detect those areas with vegetation that was severely damaged by the event. Accordingly, a fundamental question arose following this objective, namely, can we use the EVI data solely to identify the areas with severe vegetation damage? Here we report a new method for addressing this question.

[7] This paper is organized as follows. Section 2 describes the 2008 ice and snow storm event and its effects. The research data and methods used are given in sections 3 and 4, respectively. In section 5 , the results of this study are presented. A discussion is provided in section 6, and the paper ends with conclusions.

\section{The 2008 Ice and Snow Storm Event and Its Effects}

[8] The ice and snow storm event that occurred from 10 January to 2 February 2008 in southern China was catastrophic to transportation, energy supply, electric power transmission, agriculture and forest ecosystems [Ding et al., 2008]. Figure 1 shows that the event mainly affected the provinces of Anhui, Hubei, Zhejiang, Fujian, Jiangxi, Hunan, Guizhou, Guangxi and Guangdong in south China. The details of mapping the number of freezing days (noted as FDs hereafter) are given in subsection 4.1. During the event period, southern China suffered four severe consecutive ice and snow storms (see Table 1) [National Climate Center, 2008].

[9] Ding et al. [2008] analyzed the causes of this unprecedented freezing disaster, and discussed the possible association with global warming. They also revealed that there are four characteristics regarding this climate extreme. These are, first, that there were several climate extremes at a continental scale in January 2008, and the ice and snow storm event that occurred in south China was the worst in a widespread chain of events of large-scale low temperature and ice and snow storms throughout Asia. Second, within the freezing period, the weather record showed a significant temperature drop, abnormally low daily maximum temperature and unusually high amount precipitation. The intensity and persistence of the freezing weather broke historical records in many counties. This ice and snow storm event was the worst, according to national weather records, for the past five decades. Third, the freezing rain occurred mainly in Hunan, Guizhou, Hubei and Jiangxi provinces, where

Table 1. Four Ice and Snow Storms in South China During the Period of 10 January to 2 February $2008^{\mathrm{a}}$

\begin{tabular}{|c|c|c|}
\hline Period & Impact Areas & Notes \\
\hline \multirow[t]{2}{*}{ 10-16 Jan (7 days) } & South and middle Hunan, south and west Guizhou & Ice storm \\
\hline & $\begin{array}{l}\text { Henan, middle and north Anhui, north Jiangsu, } \\
\text { Hubei, north Hunan, north Jiangxi }\end{array}$ & Snow storm \\
\hline \multirow[t]{2}{*}{ 18-22 Jan (5 days) } & $\begin{array}{l}\text { South Anhui, south and middle Hunan, whole Guizhou, } \\
\text { north Guangxi }\end{array}$ & Ice storm \\
\hline & $\begin{array}{l}\text { East Hubei, south Henan, north and middle Anhui, } \\
\text { north Jiangsu, north Hunan }\end{array}$ & Snow storm \\
\hline \multirow[t]{2}{*}{ 25-29 Jan (5 days) } & Most areas of Jiangxi, Guizhou and Hunan & Ice storm \\
\hline & $\begin{array}{l}\text { South Henan, east Hubei, whole Anhui and Jiangsu, } \\
\text { north of Zhejiang }\end{array}$ & Snow storm \\
\hline \multirow[t]{2}{*}{31 Jan to 2 Feb (3 days) } & Most areas of Guizhou, Hunan, Jiangxi and Zhejiang & Ice storm \\
\hline & $\begin{array}{l}\text { Middle Hunan, north Jiangxi and Zhejiang, south Anhui } \\
\text { and Jiangsu, }\end{array}$ & Snow storm \\
\hline
\end{tabular}

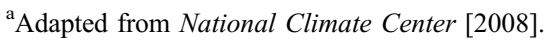


Table 2. Data Sets Used in This Study

\begin{tabular}{|c|c|c|c|}
\hline Data & Details & Period or Phases & Resolution \\
\hline Weather data & $\begin{array}{l}\text { Mean temperature Maximum temperature } \\
\text { Minimum temperature Precipitation } \\
\text { Minimum relative humidity Wind } \\
\text { direction of the maximum wind speed }\end{array}$ & 2000 to 2009 & Daily data \\
\hline MOD13A1 & EVI data Summary Quality layer & DOY49, 2000 to DOY351, 2009 & $500 \mathrm{~m}$ resolution 16 day temporal resolution \\
\hline MOD10A2 & Snow Cover data & DOY01 to DOY 57 in 2008 & $500 \mathrm{~m}$ resolution 8 day temporal resolution \\
\hline MCD15A2 & Leaf Area Index (LAI) data & DOY01, 2003 to DOY361, 2009 & $1000 \mathrm{~m}$ resolution 8 day temporal resolution \\
\hline MYD11A2 & $\begin{array}{l}\text { Land Surface Temperature and } \\
\text { Emissivity (daytime) data }\end{array}$ & DOY01, 2003 to DOY361, 2009 & $1000 \mathrm{~m}$ resolution 8 day temporal resolution \\
\hline MCD12Q1 & Land Cover Type data & 2007 & $500 \mathrm{~m}$ resolution \\
\hline Landsat & Path 123 Row 043 & $\begin{array}{l}\text { 2003-01-17 (SLC-on) } \\
\text { 2008-03-03 (SLC-off) }\end{array}$ & $\begin{array}{l}\text { Landsat } 7 \text { Enhanced Thematic Mapper } \\
\text { (ETM) } 30 \mathrm{~m}\end{array}$ \\
\hline DEM data & $\begin{array}{l}\text { NASA Shuttle Radar Topographic } \\
\text { Mission (SRTM) Dem data }\end{array}$ & & $90 \mathrm{~m}$ resolution \\
\hline
\end{tabular}

many counties recorded the historical maximum thickness of icing on the electrical wires. Finally, persistent freezing rain was the dominant factor responsible for the severe damage to vegetation in southern China.

[10] The 2008 climate extreme in south China damaged 20.86 million hectares of forests and plantations, which is roughly equivalent to the number of hectares that were reforested between 2003 and 2006 in the whole of China [National Climate Center, 2008; Stone, 2008]. In Hunan Province, more than 2.5 million hectares of forest and plantations were severely damaged; in Jiangxi, almost $30 \%$ of the forest was destroyed, and over $70 \%$ of the bamboo forest was affected [National Climate Center, 2008]. In the Nanling mountain area, where Hunan, Jiangxi and Guangdong provinces meet, the entire forest located between 500 and $1300 \mathrm{~m}$ was wiped out [Stone, 2008].

[11] A number of studies have been conducted to assess the 2008 ice and snow storm impacts on vegetation from various aspects. Liu et al. [2008] investigated the ice storm damage to various tree species at different locations in Hunan province, and suggested that those areas with meteorological conditions of around $0^{\circ} \mathrm{C}$ daily temperature and greater than $85 \%$ relative humidity suffered more ice damage to vegetation. Luan et al. [2008] investigated the damage of Pinus elliottii in the freezing rain and snow areas, and showed that more serious impacts occurred on trees with a Diameter Breast Height smaller than $20 \mathrm{~cm}$. Luo et al. [2008] used the field survey data in estimating the ice and snow damage to the evergreen and deciduous broadleaf mixed forest in northern Guangdong province and found that the vegetation located at altitudes of between 700 to $1000 \mathrm{~m}$ was more seriously damaged. Su et al. [2008] evaluated the snow damage to bamboo in Huangshan Mountain in Anhui province, and found that the bamboo was damaged more at altitudes of between 600 to $650 \mathrm{~m}$ than between 250 to $300 \mathrm{~m}$, and more in hills than on flat ground, and in high density compared to low-density vegetated areas.

\section{Research Data}

[12] Table 2 lists the data sets used in this study. The weather observations are used to outline the areas with different numbers of FDs. The MODIS EVI data have been used to delineate the regions with vegetation damage. The other series of MODIS products (including Leaf Area Index
(LAI), Land Surface Temperature (LST) and Land Cover Type) have been adopted to indirectly confirm the vegetation damage over the impacted areas. The Landsat data have been used to validate the results from the EVI data, and the Digital Elevation Model (DEM) data have been used to analyze the topographic features of the impacted areas.

\subsection{Weather Observations}

[13] Weather observations were collected over a Chinese national surface observational network managed by the China Meteorological Administration [Li et al., 2009]. Over south China, there are 186 weather stations (see Figure 1). At each weather station, daily maximum, minimum and mean temperatures, precipitation, minimum relative humidity and wind direction for the period of 2000 to 2009 have been used in this study.

\subsection{MODIS Products}

[14] The present study has used a series of MODIS products (see Table 2), which have been available since DOY (Day of the Year) 49 in 2000. The MODIS product that has been mainly used in this research is the MOD13A1 EVI. The quality assurance (QA) layer in MOD13A1 has also been used to judge the precision of the EVI data. There are two types of MODIS vegetation indices, the NDVI and the EVI [Justice et al., 1998]. While the NDVI is responsive to chlorophyll, the EVI is more sensitive to the variations of canopy structure, such as canopy architecture, crown type, vegetation physiognomy and LAI [Gao et al., 2000]. Furthermore, the EVI is more sensitive to variability in a densely vegetated surface than the NDVI [Huete et al., 1994]. Therefore, the MODIS EVI data set in the MOD13A1 data package, with the $500 \mathrm{~m}$ spatial and 16 day temporal resolutions, has been used to detect the 2008 ice and snow storm damage.

[15] Table 2 lists the MODIS snow data set (MOD10A2) [Hall et al., 2000], and this study has adopted it to identify the ice and snow storm impacted area during the event period and to detect the ice-free periods after the event, which can be used to comment on the quality of the EVI analysis. This data set was obtained from the National Snow and Ice Data Center (NSIDC) Distributed Active Archive Center (DAAC). The MODIS snow cover product represents the potential improvement to, or enhancement of, the currently available operational products mainly because MODIS has the capability to separate snow and clouds [Hall and 


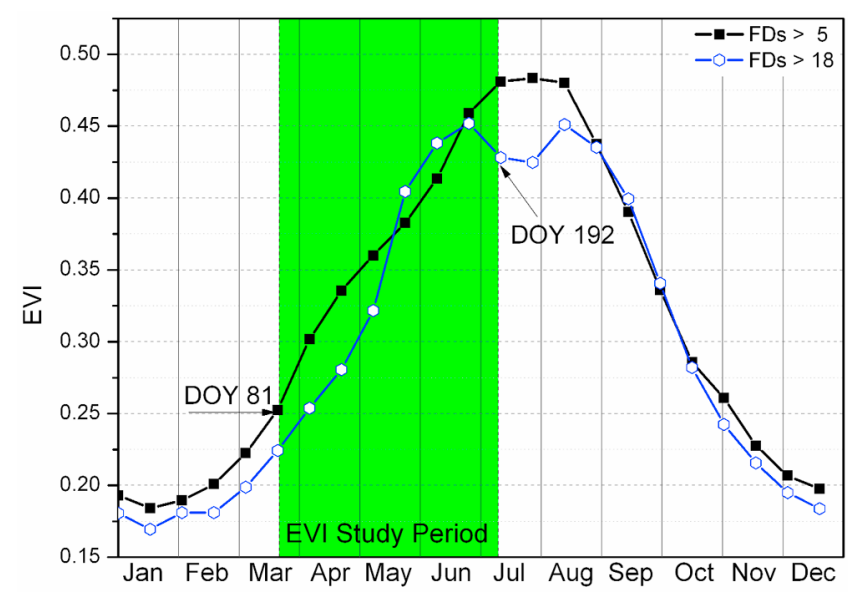

Figure 2. Seasonal variations of EVI over the two areas with at least 5 and 18 freezing days (FDs), respectively. The shaded span is the EVI study period (DOY81 to DOY192), which is the part of vegetation growing season.

Riggs, 2007]. The maximum snow cover extent in January and February of 2008 has been applied to discriminate the ice and snow cover regions over south China.

[16] The two other MODIS products, LAI (MCD15A2) and LST data (MYD11A2), have been used to confirm the detected areas with severe ice and snow storm damage to vegetation. It is worth noting that the two data sets have been available since 1 January 2003 and that the temporal and spatial resolutions are 8 day and $1 \mathrm{~km}$ (see Table 2), respectively. In addition, the MODIS Land Cover Type annual data set (MCD12Q1) in 2007 has been used to identify the land cover types, which are classified according to the International Geosphere-Biosphere Programme (IGBP).

\subsection{Landsat Images}

[17] To view the vegetation damage over those areas with the ice and snow storm impacts, the Enhanced Thematic Mapper (ETM) images with a high spatial resolution $(30 \mathrm{~m})$ from Landsat 7 have been used. These images were obtained from the Global Land Cover Facility website (http://www. landcover.org). Unfortunately, since 31 May 2003, the ETM Scan Line Corrector (SLC) has not been functioning (Landsat 7 science data users handbook, NASA, http:// landsathandbook.gsfc.nasa.gov/handbook.html, accessed 2004), a condition referred to here as SLC-off. The SLC was used to compensate for the forward motion of the satellite during data acquisition. As a result of the SLC-off, there is a gap between two swaths of images. In this study, the prestorm image was acquired on 17 January 2003, which is a SLC-on scene. The poststorm SLC-off image was acquired on 3 March 2008. An algorithm described by J. G. Masek (2007), White paper on use of gap-filled products for the middecadal Global Land Survey, http://gls.umd.edu/documents/ MDGLS_gapfill.pdf has been used to fill the gaps in the poststorm image.

\subsection{Digital Elevation Model Data}

[18] The topographic features of the vegetation-impacted areas, due to the ice and snow storms, have been explored by using the DEM data obtained from the NASA Shuttle
Radar Topographic Mission (SRTM), which were downloaded from the Consortium for Spatial Information (CGIAR-CSI) website (http://srtm.csi.cgiar.org/). The SRTM data are available at the 3 arc second (approximate $90 \mathrm{~m}$ resolution) spatial resolution. To match the EVI data resolution, the 3 arc second data have been resampled into the $500 \mathrm{~m}$ resolution, and then the land surface aspects and slopes have been calculated by using the $500 \mathrm{~m}$ resolution DEM data.

\section{Methods}

\subsection{Number of Freezing Days}

[19] At each weather station (see Figure 1), the number of FDs over the event period has been calculated according to the definition given by the National Climate Center [2008], which regards a day as an FD, if the precipitation depth is larger than $0 \mathrm{~mm}$ and the daily mean temperature is below $1{ }^{\circ} \mathrm{C}$. This study has also adopted an inverse distance weighting interpolation method to generate a grid map of the number of FDs over south China (see Figure 1) from the point samples.

[20] Figure 1 shows that the worst event-impacted area with more than 18 FDs is the center of Hunan province. The area with 13 to 18 FDs in southern China is a belt from southwest to northeast, which is mainly in Hunan, Anhui, Jiangxi, Hubei and Guizhou provinces. During the event period, many weather stations over these provinces reported historic records of freezing rain depths. In the northern freezing belt of Hubei, Anhui and Zhejiang, there were mainly snow storms, instead of ice storms (see Table 1 for details).

\subsection{EVI and Study Period}

[21] The EVI is designed to optimize the vegetation signal with improved sensitivity in high biomass regions and improved vegetation monitoring through a decoupling of the canopy background signal and a reduction in atmosphere influences [Huete et al., 2002]. The equation for computing the EVI is given below [Huete et al., 1994, 2002]:

$$
E V I=G \frac{\rho_{\text {NIR }}-\rho_{\text {red }}}{\rho_{\text {NIR }}+C_{1} \times \rho_{\text {red }}-C_{2} \times \rho_{\text {blue }}+B}
$$

where $\rho_{\text {NIR }}, \rho_{\text {red }}$ and $\rho_{\text {blue }}$ are atmospherically corrected or partially atmosphere corrected (Rayleigh and ozone absorption) surface reflectances for the NIR, red and blue bands, respectively. $B$ is the canopy background adjustment that addresses nonlinear, differential NIR and red radiant transfer through a canopy [Huete et al., 1994]. $C_{1}$ and $C_{2}$ are the coefficients of the aerosol resistance term, which uses the blue band to correct for aerosol influences in the red band. $G$ is the gain factor. The coefficients adopted in the MODIS-EVI algorithm are $B=1, C_{1}=6, C_{2}=7.5$, and $G=$ 2.5 [Huete et al., 1994].

[22] The MOD13A1 EVI data with a 16 day time step for the period of 2000 to 2007 are averaged for the two areas, which are with more than 18 FDs and 5 FDs, respectively (see Figure 1). Figure 2 shows the two EVI series for both of the areas, and it can be observed that from DOY17 to DOY192 the EVI values increase continuously, which refers to the vegetation growing season. From inspection of the data from the MOD10A2 Snow Cover product, south China 
was mostly covered by cloud and ice and snow during the ice storm period, 10 January to 2 February 2008. The MODIS EVI QA data also indicate that the EVI data at DOY17 and DOY33 are not reliable. Furthermore, during the event period, because the EVI values are rather small (see Figure 2), the ice and snow storm damage to vegetation is not easily detectable. Therefore, the EVI study period used in this study is from DOY81 to DOY192 (see Figure 2), and the Snow Cover data indicate that during this period in 2008 the ground surface was ice-free. Consequently, there are totally seven 16 day EVI phases, i.e., DOY81, DOY97, DOY113, DOY129, DOY145, DOY161 and DOY177 phases. It is worth noting that the EVI DOY81 phase is the period of DOY81 to DOY96, and the DOY177 phase the period of DOY177 to DOY192.

\subsection{EVI Statistical Terms}

[23] To evaluate the damage of the 2008 ice and snow storms to vegetation, various EVI statistical terms have been computed. For the whole EVI study period of DOY81 to DOY192, at each pixel, the average EVI value, $\bar{e}(i)$, has been calculated. $\bar{E}$, the average $\bar{e}(i)$ from 2000 to 2007 , has then been computed to represent the normal vegetation status,

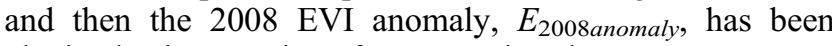
obtained. The equations for computing these means, anomaly values and related standard deviations are given below:

$$
\begin{gathered}
\bar{e}(i)=\frac{1}{7} \sum_{j=1}^{7} \operatorname{EVI}(i, \operatorname{DOY}(81+(j-1) \times 16)), \\
i=2000, \cdots, 2008 \\
\bar{E}=\frac{1}{8} \sum_{i=2000}^{2007} \bar{e}(i) \\
E_{2008 \text { anomaly }}=\bar{e}(2008)-\bar{E} \\
E_{\text {std }}=\sqrt{\frac{1}{8-1} \sum_{i=2000}^{2007}(\bar{e}(i)-\bar{E})^{2}}
\end{gathered}
$$

where $j$ refers to one of seven EVI study phases (i.e., DOY81, DOY97, DOY113, DOY129, DOY145, DOY161 and DOY177 phases).

[24] Besides the computation of statistical terms for the whole study period, at each EVI study phase, the EVI statistical values have been calculated for every pixel. The computational equations for each 16 day EVI phase are

$$
\begin{gathered}
\bar{S}(j)=\frac{1}{8} \sum_{i=2000}^{2007} \operatorname{EVI}(i, \operatorname{DOY}(81+(j-1) \times 16)) \\
j=1, \cdots, 7 \\
S_{\text {anomaly }}(i, j)=\operatorname{EVI}(i, \operatorname{DOY}(81+(j-1) \times 16))-\bar{S}(j) \\
i=2000, \cdots, 2008 \\
S_{\text {std }}(j)=\sqrt{\frac{1}{8-1} \sum_{i=2000}^{2007}(\operatorname{EVI}(i, \operatorname{DOY}(81+(j-1) \times 16))-\bar{S}(j))^{2}}
\end{gathered}
$$

where $\bar{S}(j)$ is the average EVI at phase $j$ over the period of 2000 to 2007 . $S_{\text {anomaly }}(i, j)$ and $S_{\text {std }}(j)$ are the related EVI anomaly and standard deviation.

\subsection{LAI and LST Anomalies}

[25] The variations of LAI and LST data can be used to evidence forest disturbances. Since the available MODIS data sets for LAI and LST have an 8 day temporal resolution, the seven EVI phases are equivalent to fourteen LAI and LST phases. For the whole phase period of DOY81 to DOY192, the anomalies for the MODIS LAI and LST data in 2008 have been computed as follows:

$$
\begin{gathered}
\bar{l}(k)=\frac{1}{14} \sum_{j=1}^{14} \operatorname{LAS}(i, \operatorname{DOY}(81+(k-1) \times 8)), \\
i=2003, \cdots, 2007 \\
\bar{L}=\frac{1}{5} \sum_{i=2003}^{2007} \bar{l}(i) \\
L_{2008 \text { anomaly }}=\bar{l}(2008)-\bar{L}
\end{gathered}
$$

where $L A S$ is LAI or LST variable, and $k$ refers to one of 14 phases. By using equation (11), the variations of LAI and LST in the phase period of 2008, against the normal status in the period of 2003 to 2007, can be detected.

\section{Results}

\subsection{Delineation of Vegetation-Impacted Areas}

[26] To evaluate the damage from the 2008 ice and snow storms, the EVI normal status, represented by the years 2000 to 2007, and the 2008 anomaly over the period of DOY81 to DOY192 have been computed for identifying extensive vegetation-impacted areas (noted as EVIAs hereafter). Figures $3 \mathrm{a}$ and $3 \mathrm{~b}$ show the $\bar{E}$ and $E_{2008 \text { anomaly }} / E_{\text {std }}$ (see equations (3), (4) and (5)), respectively, in south China. From comparison of Figure 3 with Figure 1, it can be observed that the $\bar{E}$ values inside the areas with more than 18 FDs (also see the contour lines in Figure $3 \mathrm{~b}$ ) are relatively small (see Figure 3a). The identification of the areas with the $E_{2008 \text { anomaly }}$ below zero provides a general picture of the vegetation-damaged areas in south China.

[27] For comparison purposes, the areas with $E_{2008 \text { anomaly }} /$ $E_{\text {std }}$ below -0.2 (the reason for selecting this value will be addressed later) are regarded as the EVIAs (see Figure 3b). From inspection of the EVIAs, it can be found that these areas are mainly located in the regions with less than 13 FDs and with high $\bar{E}$ values. In addition, the study area (see the rectangular box in Figure 3a), which covers most of these EVIAs, has been identified and selected. However, the criterion of delineating the vegetation-damaged areas due to the ice and snow storms cannot be easily set up by using $E_{2008 \text { anomaly. }}$ This is because, since the $E_{2008 \text { anomaly }}$ computed by equation (4) is an averaged EVI value over the seven 16 day phases, it is possible that a vegetation patch without severe damage is included into the EVIAs, maybe due to some EVI phases over the patch being considerably below zero. Therefore, a method has been developed in this 


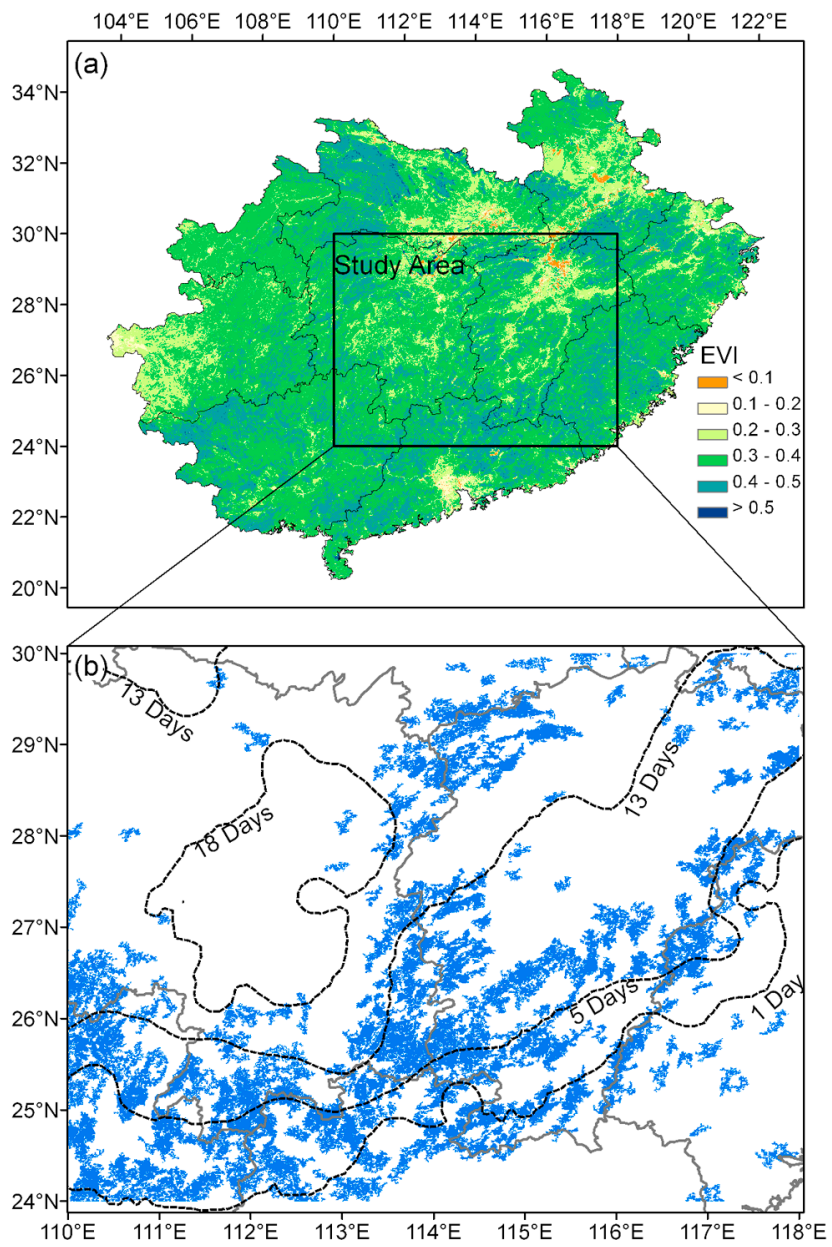

Figure 3. (a) Average EVI values over the EVI study period are calculated by equation (3), and the rectangular box is the location of the study area (latitude between $24^{\circ} \mathrm{N}$ and $30^{\circ} \mathrm{N}$, and longitude between $110^{\circ} \mathrm{E}$ and $118^{\circ} \mathrm{E}$ ) in south China. (b) The shaded areas are the Extensive VegetationImpacted Areas (EVIAs), and the contour lines represent the number of freezing days (see Figure 1).

study to detect the severe vegetation-impacted areas (noted as SVIAs hereafter), and this is outlined next.

[28] Over the study area (see Figure 3), the areas with the $S_{\text {anomaly }}(i, j) / S_{\text {std }}(j)$ (see equations (7) and (8)) below 0 , $-0.05,-0.1,-0.2, \ldots$, and -1.0 , respectively, for all seven EVI study phases have been computed for each year from 2000 to 2008 (see Figure 4). From Figure 4, it can be found that the areas in 2008 are considerably larger than those observed in other years, which indicates the ice and snow storm impacts. However, from 2000 to 2007, those areas with negative of $S_{\text {anomaly }}(i, j) / S_{\text {std }}(j)$ are still rather large. With a careful inspection of these values in Figure 4, the criterion of the pixels with $S_{\text {anomaly }}(2008, j) / S_{\text {std }}(j)<-0.2$ for all the seven phases has been selected to delineate the SVIAs due to the 2008 extreme event. The reason for using -0.2 is that for this value the area in 2008 is still large (nearly, $10000 \mathrm{~km}^{2}$ ), and the areas for the other years are relatively small, being less than $3000 \mathrm{~km}^{2}$.

[29] Figure 5a shows the SVIAs in the study area (see Figure 3), and it can be found that all of the SVIAs are located at mountainous regions, along with Nanling Mountain, Luoxiao Mountain and Wuyi Mountain, which are located along the borders of Hunan, Jiangxi, Guangdong and Fujian provinces. Figure $5 \mathrm{~b}$ gives the details of a region with the SVIAs in the Nanling National Forest Park (NNFP) region, which reveals that most of these areas are located in moderate elevation regions. A further analysis of the topographic features of these areas is given in subsection 5.4.

\subsection{Confirmation of the Impacted Areas}

[30] To validate the method of delineating the SVIAs, the Landsat 7 ETM images over the NNFP region (Figure 5b) for 17 January 2003 (see Figure 6a), prestorm, and on 3 March 2008 (see Figure 6b), poststorm, have been compared. The SVIAs are outlined in Figures $6 \mathrm{a}$ and $6 \mathrm{~b}$, and it can be found that the damage to the vegetation, which is reflected by the "browning" of green vegetation over the SVIAs in Figure $6 \mathrm{~b}$, is observable. Also, the EVIAs over the Landsat images (not shown here) have also been checked, and it is found that all of the SVIAs are included in the EVIAs. Nevertheless, some patches in the EVIAs do not show the "browning" of vegetation. Therefore, the comparison of the Landsat images discloses that the SVIAs, instead of the EVIAs, can be used to outline the areas with severe vegetation damage.

[31] Vegetation damage can cause changes to the LAI and the LST. Since the vegetation canopies and trees can be substantially lost due to the severe ice and snow storms, the related LAI will decrease, and, since the vegetationdamaged area is not able to cool the land surface effectively, the related LST will increase. To confirm these, Figures $6 \mathrm{c}$ and $6 \mathrm{~d}$ show the MODIS LAI and LST anomalies computed by equation (11), respectively. It can be found that there is a significant decrease in LAI over the SVIAs after the 2008 ice and snow storms, and that most of the SVIAs have a decline of LAI of more than one (see Figure 6c). In addition, from Figure 6d, it can be observed that the LST was elevated significantly, and that the temperature in most of the SVIAs increased by more than three degrees Celsius. The

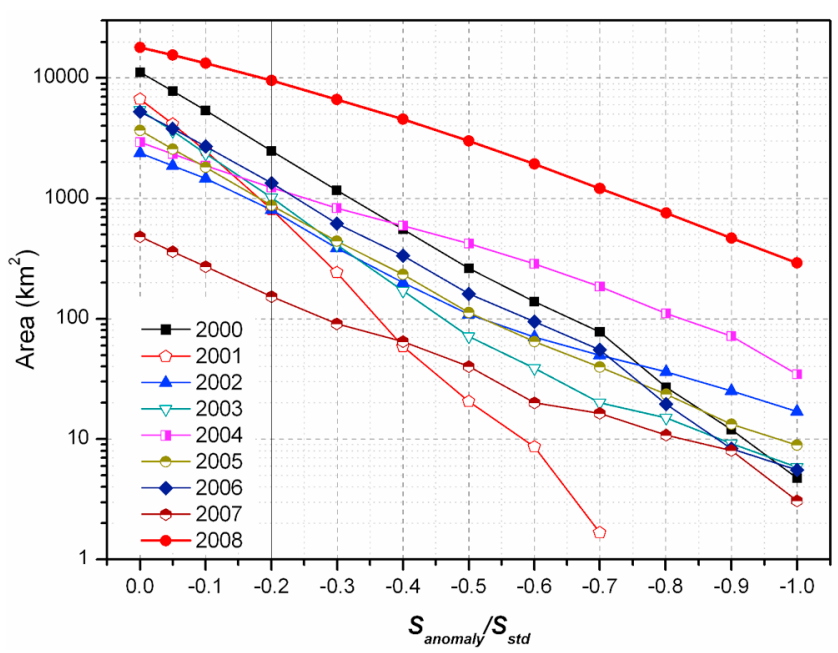

Figure 4. The Severe Vegetation-Impacted Areas (SVIAs) are calculated by using different criteria (of $S_{\text {anomaly }} / S_{\text {std }}$, using equations (7) and (8)) from 2000 to 2008 in the study area. 

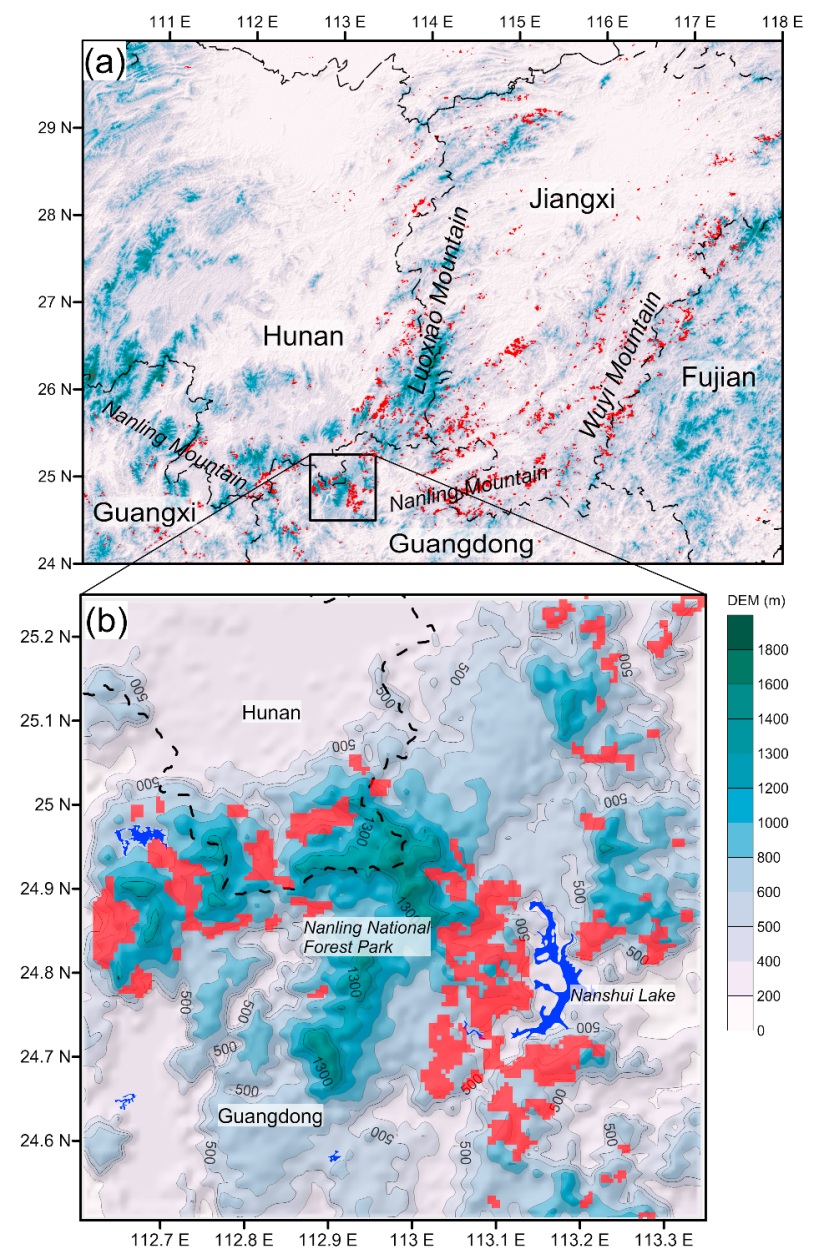

Figure 5. (a) The distribution of Severe VegetationImpacted Areas (SVIAs) shaded in the study area and (b) a zoom-in view of the SVIAs in the Nanling National Forest Park (NNFP).

results of using the LAI and LST further validate the method of delineating the SVIAs developed.

[32] To gain more insights into the vegetation damage, Figure 7a shows the EVI anomaly time series from 2000 to 2009 over three regions, the area with more than 18 FDs, EVIAs and SVIAs, and the period of 2008 is shaded gray. Figure $7 \mathrm{~b}$ displays the time series of $S_{\text {anomaly }}(2008, j) / S_{\text {std }}(j)$ over the three regions for the period of 2008 to 2009 , and includes the QA series, which are the percentages of the study area computed by using the MOD13A1 acceptable QA data. From Figure 7, it can be observed that, after the 2008 ice and snow storms, the EVI anomalies in the SVIAs are mostly below normal until the spring of 2009, except for one positive anomaly in mid-October 2008 .

\subsection{Vegetation and Climate Features}

[33] Table 3 gives the land cover types in the three regions, and it can be found that the main affected land cover type is mixed forest, and the proportions of mixed forest in SVIAs and EVIAs are $75 \%$ and $61.7 \%$, respectively. It can also be observed that evergreen broadleaf forest is the second most impacted type in SVIAs with the proportion of $12.4 \%$. The land cover type of woodland savanna is the dominant in the region with more than 18 FDs, the second in EVIAs, but is only the third most impacted type in SVIAs. The Cropland/Natural vegetation mosaic is the second dominant type in the region with more than 18 FDs, but not in SVIAs and EVIAs.

[34] To explore the weather features associated with severe vegetation damage, the weather variables including precipitation, minimum relative humidity $(\mathrm{mRH})$, maximum and minimum temperatures (Tmax and Tmin), over the SVIAs during the event period, have been analyzed. Figure 8a shows the histogram of the area percentages of the SVIAs with the accumulated precipitation depth over the event period, and it can be found that about $65 \%$ of the SVIAs received a precipitation depth of between 130 to $160 \mathrm{~mm}$.

[35] Figure $8 \mathrm{~b}$ displays the average $\mathrm{mRH}$ over the event period, and reveals that in the SVIAs, the mRH is not less than $60 \%$, and some $83 \%$ of these areas have an mRH of between $70 \%$ and $80 \%$. Figures $8 \mathrm{c}$ and $8 \mathrm{~d}$ give the spatial percentage of these areas for the weather variables of Tmax and Tmin, respectively. It can be found that most of the SVIAs experienced a Tmax range of between $2^{\circ} \mathrm{C}$ and $9^{\circ} \mathrm{C}$, and a Tmin range of between $-1^{\circ} \mathrm{C}$ and $4^{\circ} \mathrm{C}$. The Tmax has a broader range of values over these SVIAs than the Tmin.

\subsection{Topographic Features}

[36] The 2008 severe ice and snow storm damage to vegetation varied spatially, especially in the complex mountainous regions of southern China. The present study analyzes the features of the elevation, aspect and slope data over the study area, EVIAs and SVIAs (see Figure 9). From Figure 9a, it can be found that the SVIAs are mainly located in a specific elevation range of between 200 and $1000 \mathrm{~m}$, with the peak value of $9 \%$ at $600 \mathrm{~m}$. It is worth noting that the interval of the elevation in Figure 9a is $50 \mathrm{~m}$ and a value, for example $600 \mathrm{~m}$, represents the middle elevation of a class with a $50 \mathrm{~m}$ interval. In addition, the areas with more than $40 \%$ of the study area, EVIAs and SVIAs are below $200 \mathrm{~m}$, between 200 and $450 \mathrm{~m}$, and between 500 and $700 \mathrm{~m}$, respectively. The elevation range of the SVIAs is consistent with the studies of Luo et al. [2008] and Su et al. [2008].

[37] From Figure 9b, it can be observed that the forest damage in the SVIAs primarily occurred on the slopes with easterly, southerly, and, dominantly, southeasterly aspects. The dominant aspects over the study area and EVIAs are the northwesterly and southeasterly. In addition, from Figure 9c, it can be found that more than $60 \%$ of the SVIAs are located on slopes that range from 4 to 10 degrees, while $40 \%$ of the study areas are around 2 degrees.

\section{Discussion}

[38] The present study identified the SVIAs due to the 2008 ice and snow storm event, and these areas are not located in those regions with more than 18 FDs (see Figures 1 and 5). This reflects the fact that the vegetation damage was not only related to the ice and snow storms but also dependent on the factors of vegetation type, weather condition, and geographic location. The vegetation types vary along the altitudinal gradient [Gaston, 2000; Carpenter, 

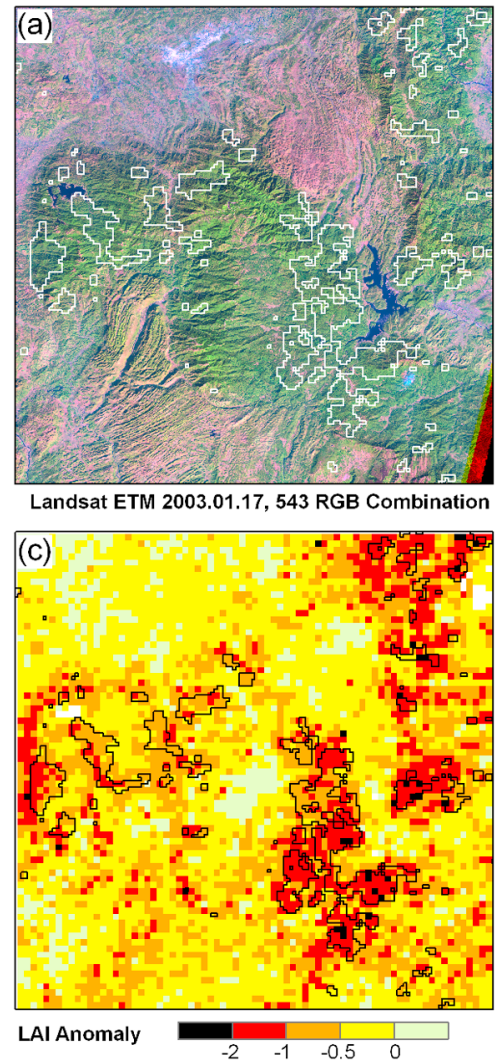
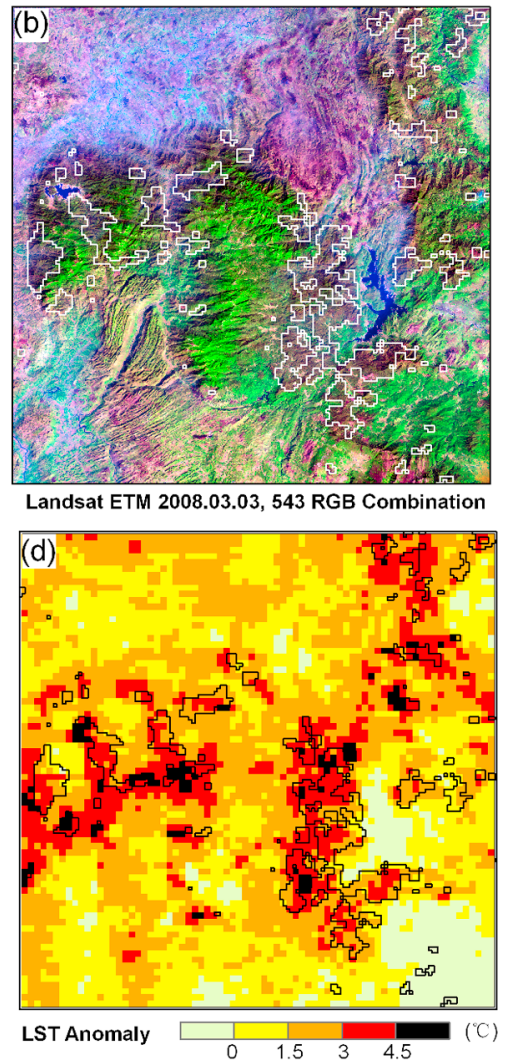

Figure 6. Confirmation of the vegetation damage in the SVIAs. (a) Landsat 7 ETM prestorm image of Path 123 Row 043 acquired on 17 January 2003. (b) Landsat poststorm image acquired on 3 March 2008. The influence of SLC-off problem (see section 3.3 for details) was removed. (c and d) The 2008 Leaf Area Index (LAI) and Land Surface Temperature (LST) anomalies for the period of DOY81 to DOY192, respectively.
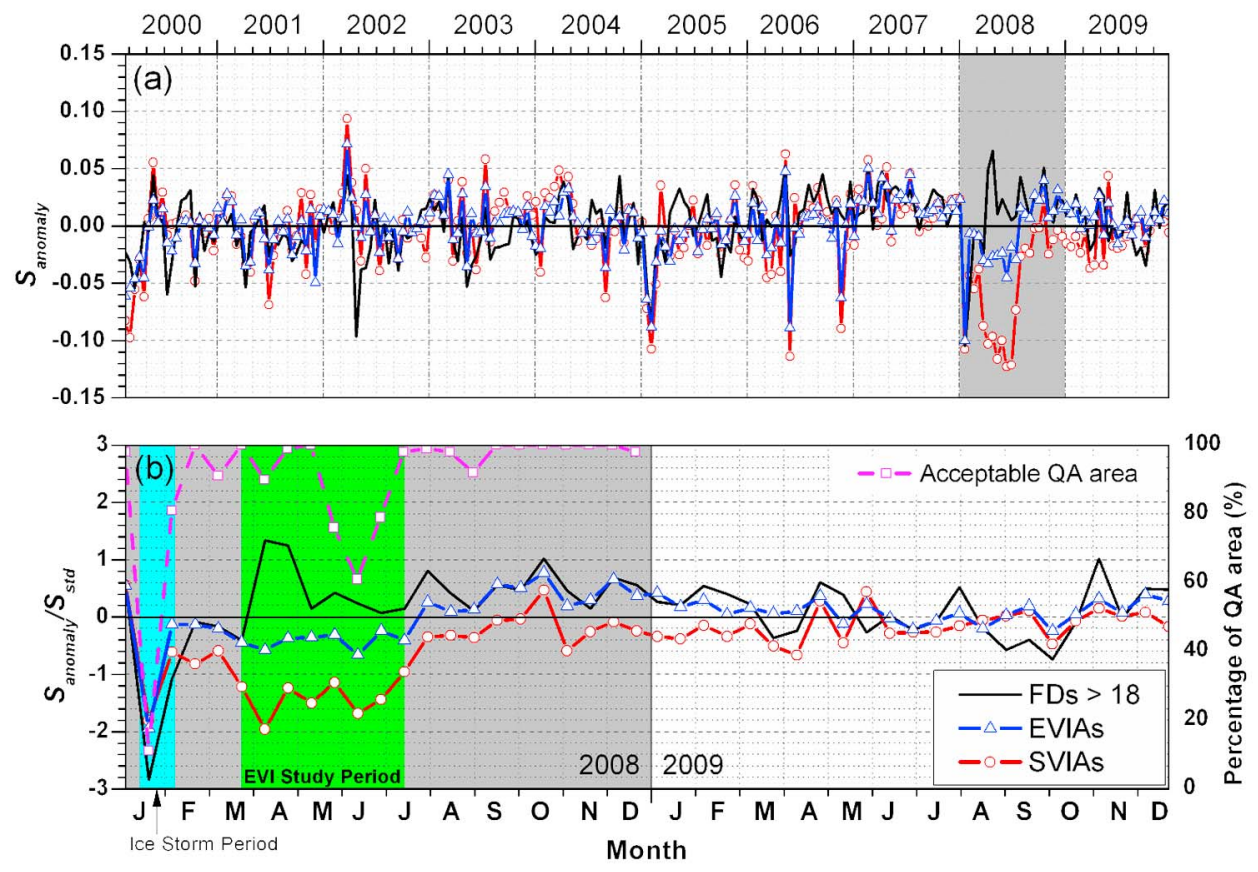

Figure 7. (a) EVI anomaly and (b) $S_{\text {anomaly }} / S_{\text {std }}$ series for three different regions, the area with more than 18 FDs, EVIAs and SVIAs, and the series of the percentage of acceptable EVI QA area over the study area. 
Table 3. Percentages of Different Land Covers in the Three Regions: Severe Vegetation-Impacted Areas (SVIAs), Extensive Vegetation-Impacted Areas (EVIAs), and More Than 18 Freezing Days (>18 FDs)

\begin{tabular}{|c|c|c|c|c|c|c|}
\hline \multirow[b]{2}{*}{ Land Cover Type $^{\mathrm{a}}$ (IGBP) } & \multicolumn{2}{|c|}{ SVIAs } & \multicolumn{2}{|c|}{ EVIAs } & \multicolumn{2}{|c|}{$>18$ FDs } \\
\hline & Area $\left(\mathrm{km}^{2}\right)$ & Percent & Area $\left(\mathrm{km}^{2}\right)$ & Percent & Area $\left(\mathrm{km}^{2}\right)$ & Percent \\
\hline Evergreen needleleaf forest & 62 & 0.7 & 953 & 0.9 & 281 & 0.6 \\
\hline Evergreen broadleaf forest & 1,174 & 12.4 & 9,733 & 9.5 & 29 & 0.1 \\
\hline Mixed forest & 7,101 & 75.0 & 63,380 & 61.7 & 5,726 & 11.5 \\
\hline Woodland savannas & 872 & 9.2 & 19,713 & 19.2 & 27,212 & 54.7 \\
\hline Cropland/Natural vegetation mosaic & 137 & 1.5 & 7,072 & 6.9 & 13,801 & 27.8 \\
\hline Others $^{b}$ & 116 & 1.2 & 1,789 & 1.7 & 2,668 & 5.4 \\
\hline Total & 9,462 & 100 & 102,640 & 100 & 49,717 & 100 \\
\hline
\end{tabular}

${ }^{a}$ The Land Cover Type is classified according to International Geosphere-Biosphere Programme (IGBP), and there are 16 land cover types.

bThe term of "other" includes all of the other land cover types.

2005] and influence the ice and snow damage. For example, this study has detected that some of the forests in the NNFP were severely damaged by the 2008 ice and snow storms. In the NNFP, the peak elevation is at Shi Keng Kong Mountain with $1902 \mathrm{~m}$. On this mountain, under $1000 \mathrm{~m}$, the main vegetation type is evergreen broadleaf, from 1000 to
$1700 \mathrm{~m}$, it is needleleaf and broadleaf mixed land cover, and, above $1700 \mathrm{~m}$, it is shrub and woodland. Figure 9a shows that the elevation range of most of the SVIAs is consistent with the results obtained by the field survey studies undertaken by Luo et al. [2008] and Su et al. [2008], which revealed that the areas with the most serious vege-
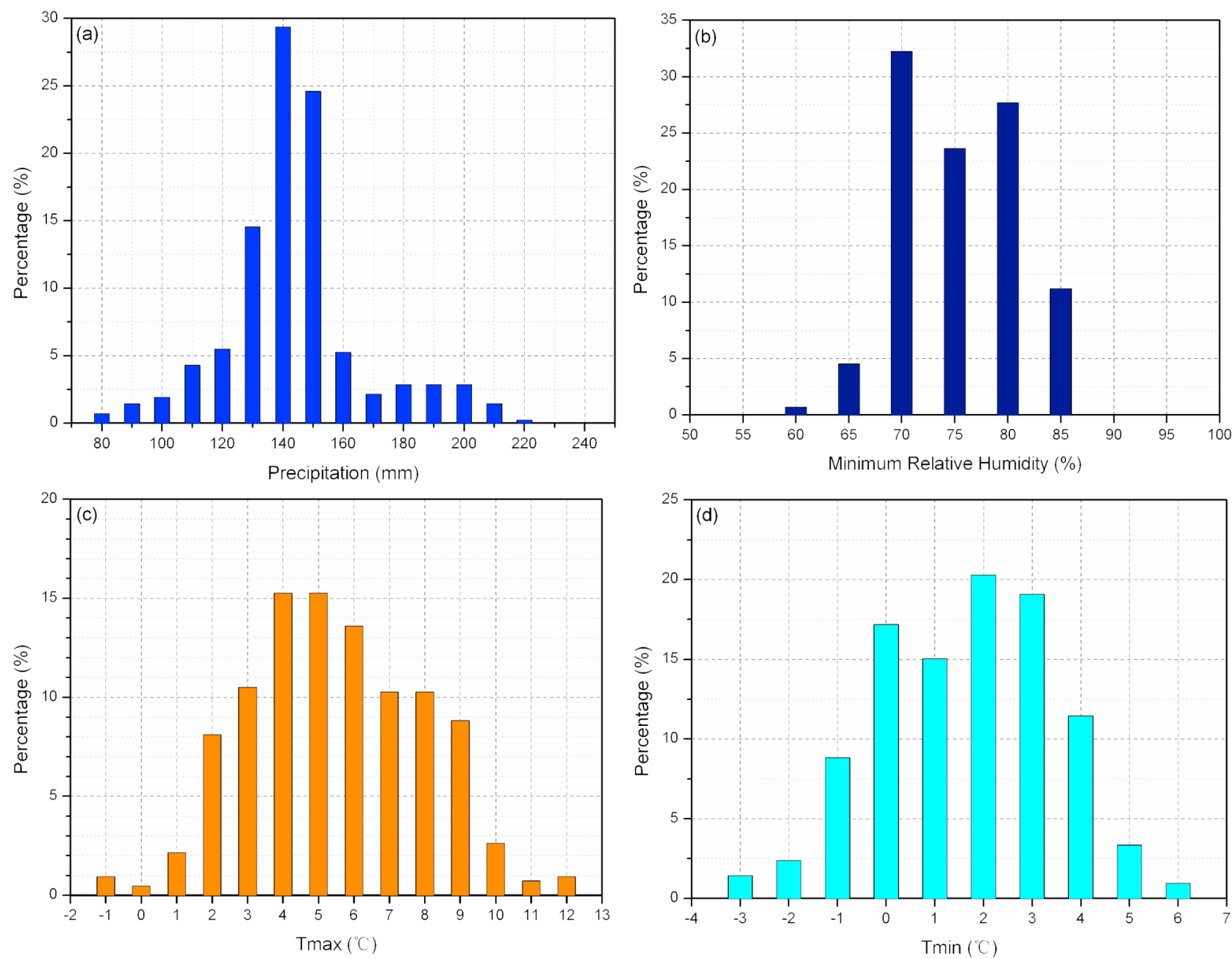

Figure 8. Statistical results for (a) Precipitation, (b) Minimum Relative Humidity (mRH), (c) Maximum Temperature (Tmax), and (d) Minimum Temperature (Tmin) for the period of 10 January to 2 February 2008 over the SVIAs. 

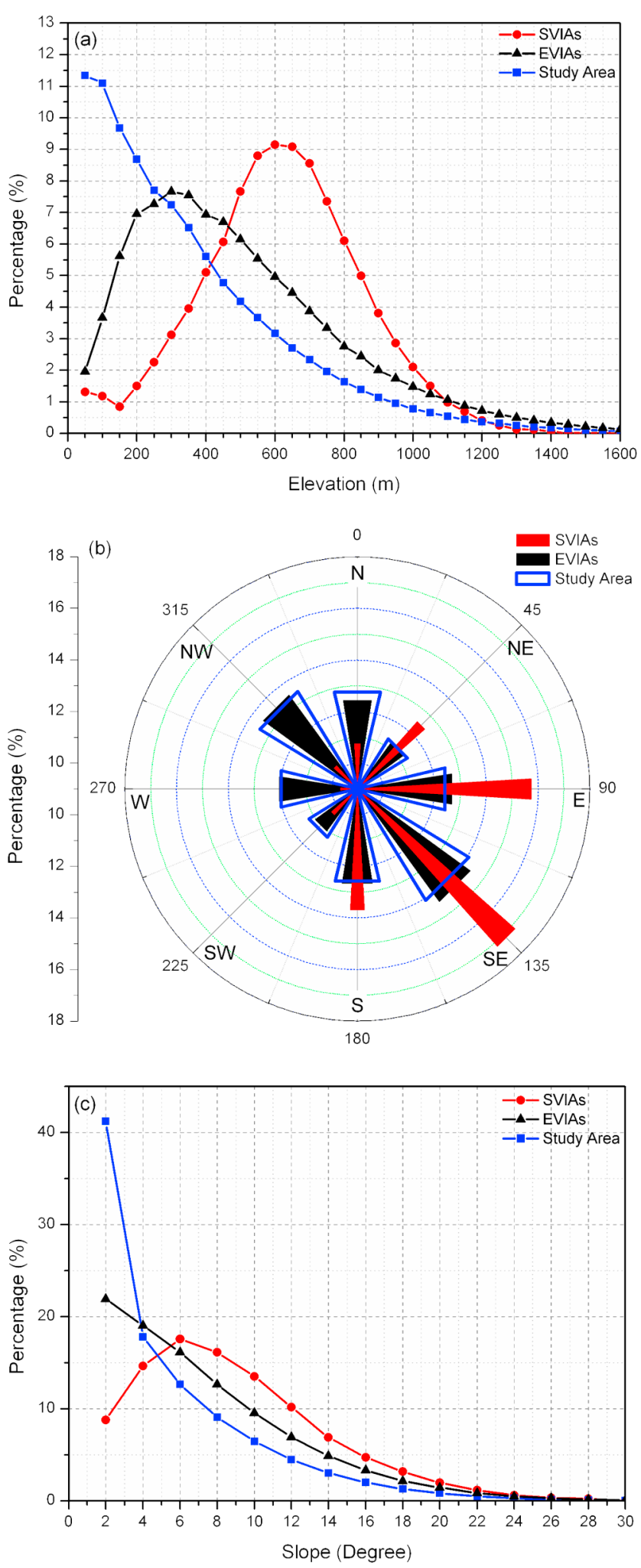

Figure 9. Topographic statistical analysis of the three regions, the SVIAs, EVIAs and study area: (a) elevation, (b) aspect and (c) slope. tation damage due to the ice and snow storm event are mainly located between 500 to $700 \mathrm{~m}$. This is mainly because in this elevation range the evergreen broadleaf is the dominant type.

[39] The evergreen broadleaf trees could intercept more snow and ice in the winter storms, and with favorable weather conditions, the icing around tree limbs could grow, resulting in severe damage. In some regions with the larger number of FDs (such as the area with more than 18 FDs), the main vegetation type is woodland savannas (54.7\%) and cropland/natural vegetation mosaic $(27.8 \%)$. In winter, there is less biomass in these land covers, and, consequently, they were less impacted by the 2008 ice and snow storms. Not only does the vegetation type play a primary role of the elevation distribution in the vegetation damage, but also the weather condition of occurring ice storms is another important factor. An ice storm can occur due to a moist warm air mass overriding a colder air mass, and the highelevation regions may be in, or just below, the moist warm air mass [Ding et al., 2008], resulting in less ice storm influence upon vegetation.

[40] The SVIAs are primarily located on those slopes with easterly, southerly and southeasterly aspects. This is consistent with the study of Stueve et al. [2007]. In the Northern Hemisphere, the vegetation usually grows well on slopes with easterly, southerly and southeasterly aspects compared to the other aspects, which is evidenced by the EVI values classified by aspect over the study area (not shown here). This study has shown that the land covers on slopes with a large biomass at these aspects are vulnerable to ice and snow storms. The wind direction observed at the weather stations (see Figure 1) over the event period has been checked in this study; however, there was no dominant wind direction for the aspects that showed severe vegetation damage. Therefore, it can be deduced that it is the vegetation density of the land surface rather than wind direction that is the important factor resulting in severe damage during the ice and snow storm event in south China.

[41] Some previous studies have used Landsat, or airborne, data to detect the forest damage [e.g., King et al., 2005; Stueve et al., 2007]. The spatial resolution of these data sets $(30 \mathrm{~m})$ is higher than that of the MODIS EVI data $(500 \mathrm{~m})$, but the method developed in this study only used the MODIS EVI data to delineate the SVIAs and EVIAs. However, it has been found that the new method is valid in outlining the patches where the severe damage to vegetation is observable. The main reason is that the intensity and persistence of the 2008 ice and snow storms in southern China were such that it was possible to use the $500 \mathrm{~m}$ spatial resolution of the MODIS EVI data. Moreover, the Landsat images and the MODIS LAI and LST anomalies were used in this study to confirm the results. However, the application of the Landsat data and MODIS LAI and LST data also discloses that it may not be possible to use only them to detect the vegetation damage, and that other environmental data are required (for example, field observations used in the study of King et al. [2005]).

[42] Compared with previous studies using Landsat and other environmental data [e.g., Olthof et al., 2004], one of the advantages of using the MODIS EVI data is that the continuous EVI curve can be generated. This is useful to study the vegetation growth after ice and snow storms, 
which can give more insight into the damage, and subsequent recovery, from weather extremes. From Figure 7b, it can be seen that the EVI anomalies in the SVIAs are mostly below normal after the event until the spring of 2009, except for one positive EVI anomaly in mid-October 2008. The reason for this anomaly might be that the understory in the SVIAs could grow well because after the loss of most forest canopies more sunlight could penetrate to the understory [Darwin et al., 2004].

[43] Regarding the application of the MODIS products, it is worth noting that the MODIS 8 day surface band reflectance data set (MOD09A1) is available, and that its temporal resolution is higher than that of the MODIS EVI product (MOD13A1) used. The present study has generated and checked the EVI data by using the 8 day surface band reflectances (MOD09A1); however, it has been found that there are abnormal variations in the time series of three bands, red, blue and NIR, used in equation (1), and related EVI (not shown here). Therefore, the MOD09A1 data could not be used to detect the ice and snow storm damage to vegetation. Although the temporal resolution of MOD13A1 is coarser than that of MOD09A1, the method developed in this study inspects most of the vegetation growing season (more than 100 days of the EVI study period (DOY81 to DOY192)) for monitoring the vegetation disturbance and the 16 day temporal resolution should be suitable. The confirmation of the SVIAs by the Landsat images and MODIS LAI and LST data is evidence that the temporal resolution of a 16 day interval used is appropriate.

\section{Conclusions}

[44] This paper has developed a new method to delineate the vegetation patches with the severe damage due to the serious ice and snow storms that occurred in southern China in 2008. The intensity and persistence of the freezing weather during the event period broke historic records in many locations. The MODIS EVI data set with $500 \mathrm{~m}$ spatial and 16 day temporal resolutions has been used to detect the vegetation damage, and then, the SVIAs due to the 2008 ice and snow storms were indentified by the new method. Most of these SVIAs are located within the elevation range of about 500 to $700 \mathrm{~m}$. Most of the EVI anomaly value of these areas did not return to positive until the spring of 2009. The obtained EVI variations after the 2008 ice and snow storms are valuable to broaden our overall understanding of the vegetation damage, which is vital to achieving more realistic predictions of vegetation disturbances and responses to weather extremes.

[45] Acknowledgments. This research was supported by the Hong Kong RGC GRF project (HKU 711008E) and the Seed Funding Programme for Basic Research in the University of Hong Kong (HKU 200911159102). The authors are grateful for the valuable comments and suggestions from the Editor, Dennis Baldocchi, the Associate Editor, and two anonymous reviewers.

\section{References}

Carpenter, C. (2005), The environmental control of plant species density on a Himalayan elevation gradient, J. Biogeogr., 32(6), 999-1018, doi:10.1111/j.1365-2699.2005.01249.x.
Darwin, A. T., D. Ladd, R. Galdins, T. A. Contreras, and L. Fahrig (2004), Response of forest understory vegetation to a major ice storm, J. Torrey Bot. Soc., 131(1), 45-52, doi:10.2307/4126927.

Ding, Y., Z. Wang, Y. Song, and J. Zhang (2008), The unprecedented freezing disaster in January 2008 in southern China and its possible association with the global warming, Acta Meteorol. Sin., 22(4), 538-558.

Frolking, S., M. W. Palace, D. B. Clark, J. Q. Chambers, H. H. Shugart, and G. C. Hurtt (2009), Forest disturbance and recovery: A general review in the context of spaceborne remote sensing of impacts on aboveground biomass and canopy structure, J. Geophys. Res., 114, G00E02, doi:10.1029/2008JG000911.

Gao, X., A. R. Huete, W. G. Ni, and T. Miura (2000), Optical-biophysical relationships of vegetation spectra without background contamination, Remote Sens. Environ., 74, 609-620, doi:10.1016/S0034-4257(00) 00150-4.

Gaston, K. J. (2000), Global patterns in biodiversity, Nature, 405(6783), 220-227, doi:10.1038/35012228.

Hall, D. K., and G. A. Riggs (2007), Accuracy assessment of the MODIS snow products, Hydrol. Process., 21(12), 1534-1547, doi:10.1002/ hyp. 6715 .

Hall, D. K., G. A. Riggs, and V. V. Salomonson (2000), MODIS/Terra Snow Cover 8-Day L3 Global 500m Grid V004, digital media, updated weekly, Natl. Snow and Ice Data Cent., Boulder, Colo.

Hauer, R. J., J. O. Dawson, and L. P. Werner (2006), Trees and Ice Storms: The Development of Ice Storm-Resistant Urban Tree Populations, 2nd ed., Joint Publ. 06-1, 20 pp., Coll. of Nat. Resour., Univ. of Wisc.-Stevens Pt. and the Dept. of Nat. Resour. and Environ. Sci. and the Off. of Cont. Ed., Univ. of Ill. at Urbana-Champaign. (Available at http://web.extension.illinois. edu/forestry/publications/pdf/urban_community_forestry/trees_and ice storms_2006.pdf)

Huete, A., C. Justice, and H. Liu (1994), Development of vegetation and soil indexes for MODIS-EOS, Remote Sens. Environ., 49, 224-234, doi:10.1016/0034-4257(94)90018-3.

Huete, A., K. Didan, T. Miura, E. P. Rodriguez, X. Gao, and L. G. Ferreira (2002), Overview of the radiometric and biophysical performance of the MODIS vegetation indices, Remote Sens. Environ., 83, 195-213, doi:10.1016/S0034-4257(02)00096-2.

Justice, C. O., et al. (1998), The Moderate Resolution Imaging Spectroradiometer (MODIS): Land remote sensing for global change research, IEEE Trans. Geosci. Remote Sens., 36(4), 1228-1249, doi:10.1109/ 36.701075 .

King, D. J., I. Olthof, P. K. E. Pellikka, E. D. Seed, and C. Butson (2005), Modelling and mapping damage to forests from an ice storm using remote sensing and environmental data, Nat. Hazards, 35, 321-342, doi:10.1007/s11069-004-1795-4.

Li, Q., H. Zhang, J. Chen, W. Li, X. Liu, and P. D. Jones (2009), A mainland China homogenized historical temperature dataset of 1951-2004, Bull. Am. Meteorol. Soc., 90(8), 1062-1065, doi:10.1175/ 2009BAMS2736.1.

Liu, X., Z. Tan, Y. Yuan, C. Zhang, and Z. Yang (2008), Meteorological reasons for forest damage by ice and snow in Hunan Province (in Chinese), Sci. Silvae Sin., 44(11), 134-140.

Luan, Q., P. Lu, F. Xiao, J. Jiang, and M. Yu (2008), Investigation on the damage of Pinus elliottii in the freezing rain and snow area and the analysis on the reason (in Chinese), Sci. Silvae Sin., 44(11), 50-54.

Luo, T., et al. (2008), Effects of the freezing rain and snow disaster to the litterfall of evergreen and deciduous broadleaved mixed forest in Yangdongshan Shierdushui nature reserve of Guangdong (in Chinese), Sci. Silvae Sin., 44(11), 177-183.

National Climate Center (2008), The Unprecedented Freezing Disaster in China in 2008 and the Climate Analysis, 159 pp., China Meteorol. Press, Beijing.

Olthof, I., D. J. King, and R. A. Lautenschlager (2004), Mapping deciduous forest ice storm damage using Landsat and environmental data, Remote Sens. Environ., 89(4), 484-496, doi:10.1016/j.rse.2003.11.010.

Ozanne, C. M. P., et al. (2003), Biodiversity meets the atmosphere: A global view of forest canopies, Science, 301, 183-186, doi:10.1126/ science. 1084507.

Sims, D. A., et al. (2006), On the use of MODIS EVI to assess gross primary productivity of North American ecosystems, J. Geophys. Res., 111, G04015, doi:10.1029/2006JG000162.

Stone, R. (2008), Natural disasters: Ecologists report huge storm losses in China's forests, Science, 319(5868), 1318-1319, doi:10.1126/science. 319.5868.1318.

Stueve, K. M., C. W. Lafon, and R. E. Isaacs (2007), Spatial patterns of ice storm disturbance on a forested landscape in the Appalachian Mountains, Virginia, Area, 39(1), 20-30, doi:10.1111/j.1475-4762.2007.00722.x. 
Su, W., S. Fan, W. Zhang, L. Qi, and F. Guan (2008), Damage of frost and snow disaster to moso bamboo stands and the influencing factors in Huangshan, Anhui Province (in Chinese), Sci. Silvae Sin., 44(11), 42-49.

Tan, Z., C. Zhang, F. Bai, X. Li, A. Shen, S. Yuan, H. Chen, J. Zuo, and $Z$. Yang (2008), Reasons of damage of forest by ice and snow, the loss evaluation as well as suggestions on reestablishment of forest after the disaster in Hunan Province (in Chinese), Sci. Silvae Sin., 44(11), 91-95.

White, A. B., P. Kumar, and D. Tcheng (2005), A data mining approach for understanding topographic control on climate-induced inter-annual vegetation variability over the United States, Remote Sens. Environ., 98, 1-20, doi:10.1016/j.rse.2005.05.017.

J. Chen and L. Sun, Department of Civil Engineering, University of Hong Kong, Rm. 603, Haking Wong Bldg., Pokfulam Rd., Hong Kong, China. (jichen@hku.hk) 